\title{
Collaborating on Critical Thinking: The Team Critique
}

\author{
Melinda Campbell ${ }^{1, *}$ \\ ${ }^{1}$ Department of Arts \& Humanities, National University, La Jolla, California 92037, USA \\ *Correspondence: Department of Arts \& Humanities, National University, 11255 N. Torrey Pines Road, La Jolla, \\ California 92037, USA. E-mail: mcampbell@nu.edu. Tel: 1-858-642-8562
}

Received: August 22, $2015 \quad$ Accepted: September 22, 2015 Online Published: November 1, 2015

doi:10.5430/jct.v4n2p86 URL: http://dx.doi.org/10.5430/jct.v4n2p86

\begin{abstract}
Pedagogical aspirations in the 21 st century are now centering on student satisfaction and workplace-readiness in addition to the traditional goal of excellence in individual student performance. Educational experts have identified increased peer and faculty interactivity and highly developed critical-thinking skills as essential to attaining these goals. The new pedagogical tool presented and explained here promises escalation in both synchronous and asynchronous peer interaction, accelerated development of critical-thinking skills, and opportunities for meaningful collaborative learning. The "Team Critique" is a multi-stage group activity/assignment that employs multiple aspects of critical thinking to create a jointly authored, peer-critiqued, research paper or team project that builds the specific skills most highly prized by key stakeholders in the enterprise of higher education.
\end{abstract}

Keywords: collaborative learning; critical-thinking assessment; online learning

There may be no more highly touted or generally desired set of skills than those included among the abilities, behaviors, and qualities referred to by the term, "critical thinking," which has become something of a watchword in pedagogical circles. Educators want their students to be critical thinkers, employers regularly rank critical thinking near the top of the list of qualities they look for in prospective employees, and social commentators agree that good critical thinking is essential for responsible citizenship in a free and democratic society (Clemmitt, 2015). The consensus is clear: a preponderance of pedagogical theorists and others concerned with the state of education today agree that teaching critical thinking is to do nothing less than to nurture qualities that set humans apart from all other creatures: independence of thought, rationality and reflection in decision making, enlightened understanding, and the ability to see things from diverse perspectives are just some of the rewards of learning to think critically. Few would deny the value of critical thinking in preparing students for whatever they may face, either in future academic endeavors or in many of the most important life events that require decision making or rational behavior (Tsui, 2002).

Rational analysis and evaluation as well as the creation of new ideas are all part of the critical-thinking skill set, and anyone familiar with curriculum design will recognize these as the complex cognitive capacities (or types of "higher-order thinking") that form the top of Bloom's revised hierarchical taxonomy of educational objectives (Anderson et al., 2001; Bloom, Engelhart, Furst, Hill \& Krathwohl, 1956). Given the widespread use of Bloom's taxonomy in developing learning outcomes and assessment criteria throughout most disciplines taught in higher education, it makes perfect sense that critical thinking rates at the top of the list of pedagogical desiderata. Other abilities or behaviors included in the critical-thinking skill set are problem-solving, self-reflection and reflective skepticism, questioning assumptions and intellectual authority, interpretation and context consideration, exploration of alternatives and recognition of diverse perspectives, and effective communication. But there's a problem; as we see from the numerous variety of skills and capacities encompassed by critical thinking, it is a notoriously slippery subject, and educational experts are always anxious to find new and effective tools for teaching critical thinking. We know what we want, but we do not always know how to get it.

\section{Achieving Quality through Collaboration}

\subsection{Meeting the Needs of New Learning Modalities}

Over and above the need for effective methods for teaching critical thinking in the 21 st century, there is a relatively 
new ingredient in the educational mix: the online classroom. If we want effectiveness and excellence in teaching in the world of today, we must take into account that many students will be getting their education through Web-based instruction. Educational scholars and instructional designers have been hard at work setting out guidelines and criteria for attaining excellence in teaching and learning, and most recent contributions to the literature acknowledge that any efforts at systematization and standardization of effective methods must include consideration of teaching in online classrooms. While teachers in traditional face-to-face classrooms have ways of overcoming poor quality in instructional materials through real-time personal interaction and the ability to provide immediate feedback to students, online instructors have a much harder time in this regard. Online instructors are more reliant on the quality of curriculum materials since they are at a distance from their students, and any intervention or corrections they may wish to make will involve more time and effort than in onsite situations for obvious reasons. An onsite teacher can see and sense when students in her class are puzzled or frustrated or excited to share their learning experience. But in the online medium, things are not so connected or immediate. Hence the need for high-quality learning materials is more pressing than ever given the increasing number of online courses and programs now being offered throughout higher education. If online education is to live up to its promise, quality in content is paramount.

High-quality programs....are also necessary to demonstrate that e-learning is a legitimate form of education and professional development. Even with the growing body of literature that indicates that there is no significant difference in learner achievement in distance and traditional classroom settings...distance education degrees are still perceived by many as being inferior in quality....Distance learning programs must demonstrate quality and graduate skilled and satisfied students to convince people that e-learning is valid. (Hirumi, 2005)

While the move to online education has been accompanied by an increase in the discussion of pedagogical procedures, goals, and guidelines, there is a noticeable silence when it comes to specific suggestions of ways to implement these (Xu \& Morris, 2007). The intention here is not to add to the mounting pile of exhortations and generic advice calling for successful educational strategies for teaching critical thinking and enhancing student engagement and satisfaction while failing to offer any concrete methods or tools. The purpose here is to offer up a real solution, in the form of a strategic and widely applicable learning and assessment tool, to the problem of how to teach critical thinking and increase interactivity and engagement that works in all modalities, with a special emphasis on effectiveness in the online classroom. Xu and Morris (2007) point out that the content delivered in a course, whether online or onsite, is always based on specific learning outcomes and course goals. However, when a course is online, much greater emphasis on meaningful interactivity related to content delivery is necessary to compensate for the loss of the immediacy and emotional and interpersonal impact of the traditional bricks-and-mortar classroom.

\subsection{Intentional Design of Practical Solutions}

In addition to the goals and positive outcomes valued by most educators today, there is also a pressing need to challenge students to go beyond merely reporting information when asked to consider and take a position on important course-related issues. In this age of immediate and universal access to a plethora of information on nearly any subject, the basic skills of researching and reporting answers to questions based on course content do not have the same importance they once did. Ask any higher-education teacher what the most difficult task is for the majority of students, and he or she will likely single out the ability to take a rationally justified, significant, specific, and original stance on an issue. Students today have little problem finding and reporting what others think and say, but most do not have an easy time with original, creative, critical thinking. The new learning tool proposed here lays out a strategy for using collaboration in the process of absorbing, understanding, and applying course content, but beyond this, it also compels students to think deeply and critically about their own and their peers' efforts in response to the problems they have been asked to solve. The "Team Critique" is a multi-stage group activity/assignment that results in a jointly authored, peer-critiqued research paper, annotated visual presentation, or multi-media project. In addition to increasing interactivity and student engagement with course content, implementation of this learning and assessment tool in online, hybrid, and face-to-face learning environments promises to produce significant progress in the achievement of desirable pedagogical goals such as initiation of learner-centered assignments and activities, enhancement of student motivation and engagement, and delineation of clear pathways to student success, including perception of assessment consequences as meaningful and fair (Hirumi, 2005).

Educational scholars, researchers, instructors, and instructional designers are in broad agreement about how to achieve success in the classroom. Consider the following list of goals applicable to most higher-education learning situations: 
- Learners' needs should be of central importance;

- Course learning outcomes, learning objectives, and course goals should be stated clearly at the outset of a course;

- Course assignments and assessments should align with learning outcomes;

- Relation of assignments to the achievement of learning outcomes and goals should accompany assignment descriptions;

- Mode of delivery of course elements such as content modules, instructional materials, learning activities, and assessment tools should be reflective of distinct learning environments;

- Multiple learning styles should be engaged by all or most instructional materials;

- Timely, useful, and individualized instructor feedback should accompany grades on all important student work;

- Assignments and activities throughout a course should engender high levels of interpersonal interaction at multiple levels (instructor-class, instructor-individual student, student-student);

- Evaluations of student work and grade justifications should align with learning objectives and follow a logical and standardized rubric that is published at the start of the course.

(Fabry, 2009; Saulnier, Landry, Longenecker, \& Wagner, 2008; Koszalka \& Ganesan, 2004; Edmondson, 2007). The Team Critique assignment is intentionally designed to address these (among other) goals, and its implementation provides a practicable solution to achieving them.

\section{Why Teamwork Works}

\subsection{Learning through Collaboration and Cooperation}

Collaborative or cooperative learning is becoming more widely acknowledged as a useful approach for success in the online classroom. Laying out a convincing case for the advantages offered by learning tasks that incorporate collaboration or teamwork, Weidman and Bishop (2009) cite an abundance of research on the subject. They argue that one of the best ways to produce a feeling of community and create group bonding is to institute a commitment to shared goals and interdependence, and this is especially important for online environments. It is generally accepted that collaboration and cooperation in the classroom elicits higher-order thinking and increases student motivation and satisfaction (Barkley, Cross, \& Major, 2005, as cited in Weidman \& Bishop, 2009). Specifically, Weidman and Bishop outline four elements that are key to collaboration in the classroom: (a) positive interdependence, which boosts achievement; (b) individual accountability, which counteracts the "slacker factor," a common complaint against group efforts; (c) interaction that promotes others' learning, which can open up new areas of self-definition and reflection; and (d) well-developed social skills, which encourage the sort of communication and teamwork that are necessary for good decision making and conflict resolution. The authors continue their advocacy of collaboration in the classroom by examining a case taken from a model of cooperative learning called the "Jigsaw Method," which requires students to work in interdependent groups as they assume different roles in the "division of labor" in the learning process. Although different in important ways from the Jigsaw model, the Team Critique incorporates the same sort of cooperative interdependence elicited by the use of Jigsaw-style assignments. The Team Critique thus fulfills the needs of the online classroom identified by Weidman and Bishop:

Although researchers have explored structured cooperative learning in online environments to some degree, the need remains for understanding how educators can best apply specific cooperative learning models, like Jigsaw, to online learning environments in ways that capitalize on and overcome the unique characteristics of this medium. (2009, p. 53)

In play for decades, the Jigsaw method, originally designed and developed by Elliot Aronson in the 1970s (Aronson, Blaney, Stephan, Sikes, \& Snapp, 1978), has a well-established reputation for allowing students to strategically investigate complex content or simply cover more material in a shorter amount of time. Moreover, it also has been shown to generate "improvements in self-esteem, group relationships, attitudes toward school, and acceptance of and ability to work with others" (Resor, 2008, p. 20). Although originally used at the elementary-school level, the Jigsaw method can be successfully employed at any level, even in the college classroom. Resor documents the positive outcomes of this method in her college history class; students reported an increase in the interest and overall appeal of the material covered and felt encouraged in their efforts at critical thinking and analysis (Resor, 2008). The Team 
Critique employs most of the powerful and beneficial components of the Jigsaw method, but it goes further by adding and essentializing the crucial element of critical thinking accessed through the detailed and multi-part critique process it brings into play. The Team Critique assignment, which can work equally well in online or face-to-face classroom situations, should be of particular interest to those hoping to bring the advantages of collaborative learning to the online environment.

Learners who thrive in environments that foster social interaction and interpersonal connections usually do well in face-to-face classroom situations, especially if the class includes group discussions or team activities. In online classes, however, such students can feel isolated and unmotivated. Ascough (2002) points out that one easy way to immediately introduce social interaction into an online class, as many instructors and instructional designers have learned by now, is to create a virtual space - a "student lounge" or informal chat room-where students can introduce themselves, exchange comments about the course or about themselves, ask questions, express opinions, share experiences, vent frustrations or vaunt achievements without the strictures of being graded or judged. It has been challenging, however, to transform the easy dynamism of such informal structures into content-rich, intellectually rigorous learning tools. It is the goal of pedagogical theorists and in-the-field teachers alike to find an instructional design that thoughtfully unites the intellectual capacities and educational proclivities of learners with course learning objectives and the overall pedagogical goals (a number of which are set out Section 1.1 above) favored by the providers of education (Koszalka \& Ganesan, 2004; Edmondson, 2007).

\subsection{Critical Thinking Is the Goal}

The term critical thinking is thrown around a lot these days, and teachers everywhere, in just about every subject, ask their students to employ critical thinking in their written work as well as in classroom discussions. What is surprising is that although students are quite familiar with this term and know that they are supposed to be engaged in this activity and demonstrate evidence of it in their work, many students, if pressed to do so, would find it difficult to say exactly what critical thinking is. What exacerbates the problem is the fact that there are various definitions of "critical thinking," and a whole host of explanations of the concept. Philosophers have their way of understanding what critical thinking is, as do educators and psychologists. A review of the literature relevant to these academic factions will reveal that there is no universally agreed-on definition or explanation of critical thinking; however, there is sufficient common ground to establish a working account of what is generally understood to be at issue when critical thinking is discussed or called for. In a recent article that looks at how peer interaction and team learning in the classroom affect critical-thinking skills, the authors state that

Critical thinking overlaps with many constructs including reflective thinking, creative thinking, problem-solving, higher-order thinking, and metacognition [thinking about thinking].... Without a clear conceptualization of critical thinking, it has been difficult for researchers and practitioners to establish appropriate instructional intentions and instruments to appropriately assess critical thinking. (Snyder and Wiles, 2015, pp. 3-4)

Despite such obstacles, however, Snyder and Wiles settle on a conceptualization of critical thinking that allows them to proceed with the task at hand. They appeal to the (1990) report of the Delphi Panel of the American Philosophical Association for a definition of critical thinking that can be applied in their research that is easily understood and likely meshes with most stakeholders' understanding of what critical thinking is. They define critical thinking as "purposeful, self-regulatory judgment which results in interpretation, analysis, evaluation, inference, as well as explanation of the evidential, conceptual, methodological, criteriological, or contextual considerations upon which that judgment is based" (as cited in Snyder and Wiles, 2015, p. 4). For the purposes of this paper, this definition of critical thinking will serve as a useful basic account of the set of skills exercised in the Team Critique assignment.

It has been observed that since teaching critical thinking skills, if not the main subject of a course, may be seen as distracting from the main course objectives or as taking up too much class time. Faculty may even be wary of student backlash from too much emphasis on critical thinking (Tsui, 2002). Noting this reticence, Tsui explains that

there is also a need to investigate how standard teaching methods can be modified and made more efficacious.....widespread efforts to heighten students' critical thinking through instructional change are more likely to come about if they involve altering commonplace teaching techniques rather than radically replacing them. (2002, p. 754)

Building on this idea, the Team Critique does indeed employ commonplace coursework-writing and discussion - but in an innovative and strategic way. It is an answer for those educators who recognize critical thinking when confronted with it, but who lack effective instructional tools for inducing it in their students. It has 
already been stated that critical-thinking skills and the cultivation of student-student and student-teacher interaction are frequently hailed as key factors in student learning and performance as well as student satisfaction. This claim is echoed by Snyder and Wiles. In their review of the literature on the extensive research done on various "instructional interventions" that can lead to measurable improvements in critical-thinking skills, they find broad agreement in the identification of "faculty and peer interaction, writing tasks and class discussions, and problem-based learning activities....[and] specifically...small-group tutorials" (pp. 4-5) as important and effective methods for encouraging critical thinking in the classroom and developing the use of such skills generally. The Team Critique is deliberately designed to comprise all of these essential elements in a single extended assignment that explicitly employs and intentionally develops critical-thinking skills throughout its several stages of completion. It is student-centered, problem-based, and requires intense and frequent faculty and peer interactions through small-group critique activities.

\section{The Team-Critique Method}

\subsection{Forming Teams and Creating Critiques}

The Team Critique is essentially a team research project. The form of this assignment can vary depending on the content, objectives, and curriculum level of the course. The outcome may be anything from a formal jointly authored research paper to a richly produced multi-media group presentation, or something in between. A list of topics based on learning outcomes or course objectives is generated by the instructor and presented on a "sign-up sheet" at the outset of the course. There should be a sufficient number of outcome-aligned topics or prompts; for example, in a class of 20-25 students, seven or eight topics would be appropriate. In order to function as an interactive task, the topic list can be posted in a threaded discussion or "blog"-style forum; each topic could have a separate discussion thread accessed through a dropdown menu of topics. Collaboration and engagement thus begin on the very first day of class as students start to think and communicate with each other about the specific topic areas of the course they initially find most interesting. Students will have a directed motivation for opening conversations with their peers before the instructor even begins to deliver course content.

In the topic-selection discussion, students are asked to introduce themselves, and after choosing a topic, give a brief explanation for their choice of topic. Each topic will be addressed by a group of three or four students, who will, through their topic choice, form the team that will jointly author a research paper, annotated visual presentation, or other multi-media project based on that topic. In this way, there is an element of self-selection and hence student-ownership in team formation. The instructor will then meet with each of the teams and help them to get organized around their new project.

\subsection{The Four Phases of the Team Critique Assignment}

Originally designed for use in a four-week, accelerated-learning course, the Team Critique is easily adapted to courses of longer duration. The assignment is broken into four main phases or stages, and instructors can best determine how much time to spend in each phase depending on the overall time frame of the course and the needs of the particular student group involved. The four phases are as follows:

3.2.1 Phase One - Team Creation, Topic Selection, and Rough Draft: Each team will be identified and assigned a private online chat room for their team. In addition to communicating through email (and telephone or text, if they wish), students can use the online course as a virtual meeting space, arranging the specific day and time according to team members' needs. For onsite classes, students may choose a local meeting site, and online chat tools, email, and mobile communication systems are also available. Since there are only three or four team members on each team, agreeing on a convenient meeting time should not be too difficult. Team members may want to take on specific roles such as "Leader," "Researcher," "Note-Taker," "Editor," "Liaison," "Narrator," etc. Students can divide up the tasks themselves and once they are created, working drafts or sections of the paper or presentation can be circulated through email or document-sharing tools within the online course or in Web-based sharing sites. The instructor can facilitate the assigning of team roles as well as providing teams with instructions or tips on how to develop a team paper or project using techniques such as brainstorming sessions, concept maps, and outlines. At this stage in the process, teacher-student interaction starts to rev up, and facilitation is key.

A rough draft of the team paper or annotated presentation is due at the end of Phase One. If the Team Critique is used in a course of longer duration, say a 16-week semester, it may be advisable to allow more time for this first phase of the process, which will require some research time. If the course is an accelerated-pace course, such as one of four weeks, allowance must be made for "promissory notes" in the rough draft on how some of the claims made or 
conclusions envisioned will be supported with further research as the assignment moves through its phases over the duration of the course. When a satisfactory first draft is completed, it will also be posted on a public site within the course or a reliable online location. One advantage of online or hybrid classes is that a secure Web location is readily available for such purposes. For onsite classes, most educational institutions now provide the means to establish a course website to store course documents and allow for communication during off-session hours. Every student in the class will now be able to view and download the rough drafts or presentation preliminaries of all teams.

3.2.2 Phase Two - Circulate Rough Drafts, External Peer Review and Critique: After reviewing the team drafts, the instructor will assign each team the rough draft or presentation project of a different team to review at the beginning of Phase Two. Over the course of the draft-review period, as in Phase One, each team will meet in their chat room (or other designated location, actual or virtual) to discuss the draft or team project they have been given to critique. In this phase of the assignment, the instructor supports the students' learning by perhaps giving a brief lecture on the nature and value of a formal critique; the instructor may also want to provide a specific format for the critique, for example an evaluation rubric or set of guidelines or critical questions that lays out specific elements of the paper or project to be reviewed. The peer critique is a very important part of the assignment because it teaches students the essential skills of critical thinking in both the reader and writer roles.

After critiquing another team's paper or project, the team will be anxious to apply the same sort of scrutiny to their own efforts and answer the same kinds of questions they posed to other teams. In a course of longer duration, it may be possible to do a second or even a third round of critiquing exchanges, adding more voices and views to the critical comments that will aid each team in the review and revision of their rough draft. Students do not often get a chance to see what their peers are doing in terms of original thinking and writing, and this aspect of the assignment provides an excellent opportunity for doing just that; the greater the variety of work they see, the better. Moreover, if any of the students participating in the assignment are themselves planning on being educators, they will get a clear preview of the sort of work that awaits them in the future.

By the end of Phase Two, each team should complete its peer critique and again post the critiqued draft or project, which may simply be the original draft with the evaluation form attached, or it may be a thoroughly marked up draft (excellent reviewing tools are available in most word-processing software that make this easy to do in digital form). In Phase Two, the instructor's role is to demonstrate how to do a thorough critique by providing a sample marked-up paper or a critiqued slide presentation featuring the type of commentary and style of critical suggestions appropriate for the level of sophistication of the students in question. All critiqued team papers and projects will be on a public page or in some way made available to the entire class, and each team can review every other team's critiques of rough drafts. This also helps develop students' critical-thinking skills since they will be able to see the way other teams have conducted their critical evaluations and compare their own critiques with other teams' critiques.

What emerges at this point in the process is a scaffolding effect for developing critical-thinking skills. Not only do students peer-review and critique other students' work, but they also now have a way to ascend to a higher level of critical reflection through critiquing other students' critiques, which will be the natural next step when the teams get their critiqued projects back for revision.

3.2.3 Phase Three - Internal Peer Review, Analysis of and Response to Critique: This is a working period. Each team retrieves its marked-up paper or critiqued presentation and makes changes and additions accordingly. While it is advisable in online courses for the instructor to hold a live chat session at least once a week, it is essential that online courses implementing this assignment include at least one synchronous class chat with each team in Phase Three as well as a live chat with the entire class, if technology permits. This class chat will give everyone a chance to share what they learned from working with other students' projects and to interact and exchange comments and information. Students can solicit additional feedback at this time as well as solidify ideas that are well received.

A new synchronous meeting tool now available in many online platforms is the electronic "whiteboard," through which participants can display a document, a visual presentation, or other digital media in real time, and multiple users can participate in editing or making notes on the displayed document or media file. The instructor will meet separately with each team to answer questions and assist the team in the task of reviewing the critique, critiquing the critique, and revising the project into a finished form. By now the team should be comfortable working together, and this phase of the assignment is a time that is ripe for significant peer communication and interaction. The online meeting room or virtual chat room is the perfect means for generating collaborative cooperation. Everyone in the meeting can be looking at the project at once, and if the class is set up for audio and/or video transmission, the whiteboard-display session will mimic in many respects a real meeting in actual space and time.

A particular benefit of this technology is that these online critiquing workshops can be easily recorded for later 
viewing. This allows for a team member who misses the session to review the recording and stay up to date with the progress of the process. The ability to record class meetings and discussions in order to make them available throughout the duration of the course cuts away the ground that certain students may try to claim as an excuse for lack of participation. If what they missed, for whatever reason, is available for accessing at any time that is convenient for students, there is really no acceptable excuse for shirking individual responsibility to the team to keep up with team activities and decisions. Recordings of one team's critiquing session may also be reviewed by other teams, and the instructor can use this resource to target those teams and individuals who need more input or guidance. For all of these reasons, it is advisable even for onsite classes to use similar tools for recording their important critiquing sessions. After the teams are satisfied with the critiquing and revising processes, they will move into the final phase, which ends with submission of the finished group project.

3.2.4 Phase Four - Final Drafts Submitted: At this point in the assignment, the teams have been working together for a significant proportion of the class, at the very least for several weeks, and they should be a "well-oiled machine" by now. This is the time to perfect the project. Because they are working as a team, the tasks that many students find onerous and often skip or do in much too cursory a fashion - proofreading for grammatical errors and checking for logical organization, proper formatting, and satisfactory documentation of all source material — can be accomplished quickly and easily by dividing them up among the group. Final drafts or finalized projects in digital formats can be submitted to the instructor either through email or an electronic repository such as a digital "Dropbox" or the assignment-submission tools featured in most online platforms.

The instructor may want to do a quick review of the final papers and projects and send them back to the teams for one more round of revisions. If this proves to be too time consuming, then this will be the final submission. If at all possible, the instructor should return the final team papers or projects before the end of the course. This will give students another round of feedback before handing in individual final papers (or "term papers"), which most college-level courses require. Having already worked on, completed, and received feedback on a research paper or final project will give students a leg up on completing the same sort of assignment individually. They will also have participated in a process that teaches them best practices for the creation of any academic assignment they will be doing in the future, whether in a team or on their own. They will have had the opportunity to see how others tackle academic projects, solve problems, and manage effective communication. They will have learned how using various elements of critical thinking in direct application to the same sorts of coursework they may have done before, perhaps with less successful results, improves the quality of the finished product; now they will have a genuine understanding of the value of critical thinking. They will have jointly authored or created an academic product that is likely to be of higher quality, or at least more thoroughly thought-through, than any of their previous work. They can take all of these lessons with them into their next assignment or future classes.

Instructors who use the Team Critique assignment may want to decrease the word-count minimum on individual final papers or eliminate a discussion assignment so as not to overload students with too much work. The team assignment can be structured, through topic selection, to cover content areas addressed in discussion boards or other content-based assessments. Finally, the Team Critique should count for a significant proportion of the course grade (anywhere from 15\%-30\% would be appropriate). For example, if the entire assignment is worth 30 points out of a total of 100 points possible for the course, the first draft or submission might be worth 5 points, the critique worth 10 points, and the final paper or project worth another 15 points.

\section{Discussion}

\subsection{The Team Critique Meets Multiple Goals}

Active peer collaboration and social interaction on specific instructional tasks or course assignments is a significant factor in successful learning in online environments (and it can be safely assumed that the same holds true for onsite-classroom situations). Koszalka and Ganesan (2004) point out that effective learning comes about in ways other than simply taking in and comprehending new information. Learning takes hold when the needs of learners are addressed, and learning

grows out of conversation and shaping of understanding through interactions with the content and others in the learning environment. Thus, the instructional design focus of online instruction must be to engage learners purposefully and strategically in integrated interactions with content, activities, peers, and with the instructor ultimately facilitating the learning process (p. 244).

Although developed independently of any of the sources cited here, the Team Critique learning tool was originally 
designed with precisely these goals in mind. It also instantiates the characteristics of successful learning as specified in the well-known ARCS model of motivational design (Keller, 1987; discussed in Hirumi, 2004 and in ChanLin, 2009): (a) gaining and sustaining students' attention; (b) making course content and modalities relevant to students' needs and interests; (c) building students' confidence in their own abilities; and (d) greater student satisfaction with their learning experience.

In addition, the Team Critique assignment features opportunities for student autonomy as well as productive facilitation by placing more of the responsibility for learning on the student; it fosters reflective, enlightened, and innovative teaching by allowing for an open approach that takes account of learners' needs, the instructor's own considered educational beliefs and teaching practices, and current research in pedagogical theory and learning design (Serdyukov \& Serdyukova, 2009; Donald, Blake, Girault, Datt, \& Ramsay, 2009). Some of the most recent research into learning at all levels makes much of the "Four C's" of learning: collaboration, communication, critical thinking, and creativity, which are widely agreed to be the most crucial of all learning and innovation skills (Partnership for 21st Century Skills, 2011). The Team Critique puts students through a process in which each of the skills or capacities that foster success in learning is accessed and exercised, and it is a method that can be implemented at any point in a student's educational career. Parlaying the concept of the "Four C's" into a more complete assessment of learning essentials, educator Deborah Owen argues for a "fifth C"- connecting:

...when students are able to make connections - to prior knowledge, to themselves and their feelings, to outside people and events - they increase their understanding of new ideas and become more adaptable....The difficulty that we have as educators is to make sure that the activities we present to students are engaging enough for the way their brains work today. (Owen, 2013, p. 42)

Citing the brain-based learning principles of Eric Jensen (see, for example, Jensen, 2005) and widely accepted scientific research about how the human brain functions to enable learning, Owen explains that quite literally, physical and chemical connections made in the brain create informational links among neurons, or what we might call "neural pathways of learning." The more often the pathways are used, and the more stimuli of various types are used to create memories, the easier it is to call up the information remembered and to use it in other applications: "...the best way for brains to remember is to pull together all aspects of experience from visual, auditory, and kinesthetic stimuli into feelings and emotions" (Owen, 2013, pp. 38-39). It is through such connections that we construct meaning and achieve the kind of understanding that is the ultimate goal or endpoint of the learning process. When students are working in teams on a research project, they are doing a whole lot more than just trying to assimilate, analyze, and synthesize relevant information all on their own; they must interact and cooperate with others in these processes. This kind of interaction automatically introduces additional learning modalities and usually evokes an array of emotions and psychological affects generated by social interaction. Through collaborative learning, students can achieve levels of learning and produce work well above what they might do on their own. And they can use this experience of high achievement as a lever to boost their individual work to similarly high levels.

By forcing the creation of teams from the very start of the class, the Team Critique generates a feeling of mutual support among students, who will begin interaction on day one. Their attention is immediately directed to course learning objectives and outcomes since these are highlighted in the selected topics around which the team papers or projects will be constructed. This single learning tool offers problem-based, student-centered learning and collaboration expressly through critical-thinking activities. Strategic alignment of learning tasks and learning objectives is an important but often overlooked pedagogical goal. This is especially crucial in distance education where students must work independently and be self-motivated to stay on track (Edmondson, 2007; Harmon \& Hirumi, 1996). A sort of camaraderie is effected as soon as the teams sort themselves out through topic selection. This very first part of the project already prompts students to engage with course content to find a topic that they may even want to pursue in other assignments or other courses. Contemplating the duration and various stages of the team project at the outset also helps students understand the terrain of the course and begin to formulate a strategy for how they will negotiate a successful path through it.

\subsection{A Strong Scaffold for Constructing Knowledge}

Interactive discussions are productive, but students can grow weary of the same activity week after week. Varying the types of activities and styles of assignments in a course has at least two sure benefits: boredom is alleviated, and students with different learning styles can become more engaged. The Team Critique, through its emphasis on collaboration and team effort, puts the traditional activities of reading comprehension and writing reports or doing analytical case studies in a new light. Ascough (2002) cites research that has shown that while people are likely to remember only $10 \%$ of what they read, they are likely to remember $70 \%$ of what they discuss with others, $80 \%$ of 
what they experience personally, and an impressive $95 \%$ of what they teach to others! These statistics have significant implications for collaborative learning, and in particular for the proposed Team Critique learning tool. In this collaborative project, students are not only discussing their own work within their teams and with other teams, but they are also going through the experience of having their peers evaluate and comment on their work. In addition, the experience of being charged with critiquing the efforts of one's fellow students moves in the direction of teaching others. Since students will be graded on their critiques as well as on their projects, they will feel a responsibility to come from a place of at least partial knowledge in their judgments and evaluations. And because they will be critiquing work on a topic different from their own team's topic, they will cover additional course content in the process. Moreover, if students find errors in thinking, weak argumentation, or note obscurity or a lack of sufficient substance in their peers' work, it is certain that they will be much more open to comparable criticism and much better at subsequently finding similar problems in their own work.

The employment of the Team Critique (or similar collaborative learning tools) will help fulfill the educational purposes of colleges, universities, and other institutions of higher learning because it is an excellent and innovative way to place students at the center of the educational process and bring them together in their learning experience, enabling them to construct knowledge for themselves while operating in a community of inquiry that not only solves problems together but also promotes self-discovery (Saulnier et al., 2008; Wamba, 2010).

Educators, pedagogical theorists, instructional designers, and, not to be left out, the all-important stakeholders in the enterprise of higher education - the learners, the students - all share a number of goals in their respective efforts to make the educational experience successful, meaningful, efficient, and satisfying. It is important to set out criteria for excellence in education and guidelines for well-designed instruction, and a great deal of useful research is being conducted to help accomplish these ends. As a concrete contribution to this broad undertaking, the Team Critique is herein described and offered for use in the hope that its implementation will aid in the achievement of the numerous and laudable goals that so many have worked so hard to determine and define. The Team Critique incorporates numerous types of resources and learning media, integrates a variety of interactions and levels of interactivity, and calls upon multiple forms of communication that go beyond ordinary classroom exchanges. Working collaboratively and building a scaffold for learning based on mutual achievement offers a pedagogical framework that fits the future of education.

\section{Acknowledgements}

Thanks are to be given to my colleagues at National University for their interest in this research and their feedback when I presented an earlier version of this paper at our 2013 Research and Scholarship Conference in La Jolla, California, and also to those who attended a workshop I gave on how to implement the Team Critique assignment at the $44^{\text {th }}$ annual conference of the International Society for Experiential Teaching and Learning [ISETL] in Denver, Colorado, October 17, 2014. I would also like to thank my brother, Bret Strauss, for help with the technology used during the ISETL workshop.

\section{References}

Anderson, L.W., Krathwohl, D.R., Airasian, P.W., Cruikshank, K.A., Mayer, R.E., Pintrich, P.R., Raths, J., \& Wittrock, M.C. (Eds.) (2001). A taxonomy for learning, teaching, and assessing: A revision of Bloom's taxonomy of educational objectives. (Complete ed.). New York: Longman.

Aronson, E., Blaney, N., Stephan, C., Sikes, J., \& Snapp, M. (1978). The jigsaw classroom. New York: Sage Publications.

Ascough, R. S. (2002). Designing for online distance education: Putting pedagogy before technology. Teaching Theology and Religion, 5(1), 17-29. http://dx.doi.org/10.1111/1467-9647.00114

Barkley, E. F., Cross, K.P., \& Major, C.H. (2004). Collaborative learning techniques: A handbook for college faculty. San Francisco: Jossey-Bass.

Bloom, B.S., Engelhart, M.D., Furst, E.J., Hill, W.H., \& Krathwohl, D.R. (Eds.) (1956). Taxonomy of educational objectives: The classification of educational goals. Handbook 1: Cognitive domain. New York: David McKay.

ChanLin, L-J. (2009). Applying motivational analysis in a Web-based course. Innovations in Education \& Teaching International, 46(1), 91-103. http://dx.doi.org/10.1080/14703290802646123

Clemmitt, M. (2015). Teaching critical thinking. CQ Researcher, 25(14), 313-336. 
Donald, C., Blake, A., Girault, I., Datt, A., \& Ramsay, E. (2009). Approaches to learning design: past the head and the hands to the HEART of the matter. Distance Education, 30(2), 179-199. http://dx.doi.org/10.1080/01587910903023181

Edmondson, B. (2007). Utilizing multiple intelligences in e-learning design. International Journal of Learning, 13(12), $35-41$.

Fabry, D. L. (2009). Designing learning experiences for comparability across delivery methods. Journal of Research in Innovative Teaching, 2(1), 69-79.

Harmon, S. W., \& Hirumi, A. (1996). A systemic approach to the integration of interactive distance learning into education and training. Journal of Education for Business, 71(5), 267-272. http://dx.doi.org/10.1080/08832323.1996.10116796

Hirumi, A. (2005). In search of quality: An analysis of e-learning guidelines and specifications. The Quarterly Review of Distance Education, 6(4), 309-330.

Jensen. E. (2005). Teaching with the brain in mind ( $2^{\text {nd }}$ rev. ed.). Alexandria, VA: ASCD.

Keller, J. M. (1987). Development and use of the ARCS model of instructional design. Journal of Instructional Development, 10(3), 2-10. http://dx.doi.org/10.1007/BF02905780

Koszalka, T. A., \& Ganesan, R. (2004). Designing online courses: A taxonomy to guide strategic use of features in course management systems (CMS) in distance education. Distance Education, 25(2), 243-256. http://dx.doi.org/10.1080/0158791042000262111

Krathwohl, D. R. (2002). A revision of Bloom's Taxonomy: An overview. Theory into Practice, 41(4), 212-218. http://dx.doi.org/10.1207/s15430421tip4104_2

Owen, D. (2013). Another "C" for learning. Teacher Librarian, 40(5), 38-42.

Partnership for 21st Century Skills. (2009). P21 Common Core toolkit: A guide to aligning the Common Core state standards with the Framework for 21st Century Skills. [Internet]. Retrieved from: http://www.p21.Org

Resor, C. (2008). Encouraging students to read the texts: The jigsaw method. Teaching History: A Journal of Methods, $33(1), 20-27$.

Saulnier, B. M., Landry, J. P., Longenecker, H.E., \& Wagner, T. A. (2008). From teaching to learning: Learner-centered teaching and assessment in information systems education. Journal of Information Systems Education, 19(2), 169-174.

Serdyukov, P., \& Serdyukova, N. (2009). A study of instructional practices: The case for reflection and research. Journal of Research in Innovative Teaching, 2(1), 193-210.

Snyder, J. J., \& Wiles, J. R. (2015). Peer led team learning in introductory biology: Effects on peer leader critical thinking skills. Plos ONE, 10(1), 1-18. http://dx.doi.org/10.1371/journal.pone.0115084

Tsui, L. (2002). Fostering critical thinking through effective pedagogy. The Journal of Higher Education, 73(6), 740-763.

Wamba, G.W. (2010). Developing an alternative epistemology of practice: Teachers' action research as critical pedagogy. Action Research, 9(2), 162-178. http://dx.doi.org/10.1177/1476750310388054.

Weidman, R., \& Bishop, M. J. (2009). Using the jigsaw model to facilitate cooperative learning in an online course. The Quarterly Review of Distance Education, 10(1), 51-64.

$\mathrm{Xu}, \mathrm{H}$., \& Morris, L.V. (2007). Collaborative course development for online courses. Innovative Higher Education, 32, 35-47. http://dx.doi.org/10.1007/s10755-006-9033-5 